\title{
¿SOMOS DISTINTOS O ESTAMOS LOCOS? LOS DOBLES VÍNCULOS DEL FÚTBOL Y LA IDENTIDAD EN BILBAO
}

\author{
Are we different, or just crazy? \\ The double binds of football and identity in Bilbao
}

\author{
Mariann Vaczi* \\ University of Nevada, Reno (EE.UU.)
}

\begin{abstract}
Palabras clave
Fútbol

Doble vínculo

País Vasco

Identidad pertenecer a la primera división, y la identidad misma de la ciudad parecía estar en juego. Apoyado en una investigación etnográfica, este artículo indaga en la identidad colectiva como una trampa-22, un doble vínculo según la teorización de Bateson: una situación que presenta una elección inevitable entre dos resultados irreconciliables y no deseados, un dilema vital que desvela no solo los placeres sino también el sufrimiento de identidad producido por el fútbol en la sociedad vasca.
\end{abstract}

\section{Keywords}

Soccer

Double bind

Basque Country Identity

ABSTRACT: Athletic Bilbao has a unique player recruitment policy, allowing only Basqueborn players or those developed at the youth academies of Basque clubs to play for the team, a policy that rejects the internationalism of contemporary globalised sport. Despite this, the club has never been relegated from the top division of Spanish football. In 2007, however, Athletic came one game away from descending to second division, which sent the fan community into an impasse of identification. Its proud exceptionalism, the philosophy that made the club a "unique case in the world" now appeared to be in conflict with first division performance, and the identity of the city was at stake. Based on ethnographic fieldwork, this paper approaches collective identity as a Catch-22 type double bind as theorized by Bateson: an impasse that reveals not just the pleasure, but also the intense suffering identity produces in Basque soccer and society.
RESUMEN: El Athletic Club de Bilbao tiene una filosofía única: ficha solamente a jugadores que son vascos, una política que rechaza el internacionalismo del fútbol contemporáneo globalizado. A pesar de esta filosofía, el club nunca ha bajado a segunda división. Sin embargo, en 2007 el Athletic estuvo a solo un partido de bajar a segunda división, lo que obligó a su comunidad de seguidores a enfrentarse al impasse de su identificación localista. Su excepcionalismo altivo, la filosofía que hizo que el club bilbaíno se considerara «un caso único en el mundo", parecía ahora estar en conflicto con las exigencias de calidad necesarias para

\footnotetext{
* Correspondencia a / Correspondence to: Mariann Vaczi. University of Nevada, Reno. 1664 N Virginia St. Reno, NV 89557, Estados Unidos - mvaczi@unr.edu http://orcid.org/0000-0001-6007-0981.

Cómo citar / How to cite: Vaczi, Mariann (2020). ¿Somos distintos o estamos locos? Los dobles vínculos del fútbol y la identidad en Bilbao. Papeles del CEIC, vol. 2020/1, papel 221, 1-17. (http://dx.doi.org/10.1387/pceic.20758).

Recibido: abril, 2019; aceptado: octubre, 2019.
}

ISSN 1695-6494 / (c) 2020 UPV/EHU 
«Iñaki Williams hizo historia en una noche en la que no esperaba llegar al campo». Así empezaba en septiembre del 2019 el reportaje especial de ESPN sobre el fichaje del Athletic Club para los próximos 9 años de su jugador de la cantera de origen africano (Krichko, 2019). En una noche fría de febrero de 2015, Williams hizo un gol en el minuto 9 en el Estadio Olímpico de Turin. «¡He marcado! ¡He marcado!» gritó eufóricamente. Aunque los goles se celebren en todas partes, los debuts y los goles fuera de las finales rara vez hacen historia. En Bilbao, sin embargo, hay otras consideraciones más allá de la competición que pueden convertir una noche de invierno en un espectáculo histórico: Williams era el primer jugador negro que marcaba un gol en el Athletic, muy conocido por su filosofía de "solo vascos» a la hora de fichar únicamente jugadores locales en un contexto global (Groves, 2011). El gol fue celebrado como un hito histórico por parte de otros iñakis de Bilbao: los inmigrantes africanos que sobreviven en la calle como vendedores ambulantes. Durante un breve instante deslumbrante, la distancia entre el Iñaki de la pantalla y los iñakis de su propia comunidad, que le miraban desde los bares donde vendían joyería barata, no parecía ser tan abismal.

La filosofía del Athletic Bilbao de «solo vascos» provoca polémica en ocasiones. Por un lado, muchos aficionados de los demás clubes vascos de élite, como la Real Sociedad, Osasuna, Alavés o Éibar, ven con resentimiento la hegemonía del Athletic y su apropiación de la identidad "vasca» a pesar de los matices futbolísticos del país (O'Brien, 2017). Por otro lado, desde fuera del País Vasco, ocasionalmente se presentan acusaciones de exclusión racista. Ahora bien, Williams era una prueba de que la alineación del club no reflejaba una ideología racista, sino que se adaptaba a las realidades demográficas cambiantes de la provincia y del país, de la que los inmigrantes son una parte considerable'.

Estrictamente hablando, esto no es una novedad histórica. Bilbao atrajo a muchos inmigrantes a lo largo del siglo xx. Ello se constanta en el ámbito del Athletic en los primeros jugadores ingleses y especialmente en la mayoría de apellidos españoles en la lista de jugadores. Pero Williams es un hombre negro y la enorme fascinación producida por su caso muestra la perdurabilidad de las categorías raciales. El celo con el que se defendió en los medios de comunicación la «vasquitud» de Williams, bien por su nacimiento bien por haber pertenecido a su cantera, junto con sus calificaciones continuas de "diamante negro», "perla negra», o "estrella negra» terminaron confirmando en última instancia la posición de Williams fuera de una vasquitud normativa. La «agresiva ceguera al color» de los medios de comunicación era "a fin de cuentas otra forma de otredad» (Aquino, 2017: 130-131), de extrañamiento.

De todos modos, tales debates sobre etnicidad, raza e identidad son muy deseables, y la posición del Athletic Club es un catalizador único entre los demás ruedos culturales en el País Vasco (MacClancy, 1996; Walton, 2011). Durante más de un siglo ya, cuando emergen nuevos jugadores en la órbita del equipo, los bilbaínos debaten no sólo las cualidades del jugador, sino también su árbol genealógico. ¿Es vasco? ¿Es suficientemente vasco? ¿Pero qué es un vasco? Desde Higinio Ortuzar Santamaría y Cándido Gardoy Martín en el equipo inmediatamente posterior a la Guerra Civil; a Chus Pereda y Miguel Jones en los 1960; los hermanos Manolo y Lázaro Sarabia en los 1970; Bixente Lizarazu en los 1990; Diego Forlán y Ander Herrera en los 2000; y hasta, por supuesto, Williams en la década de 2010, el Athletic ha contribuido ampliamente a definiciones de qué significa ser "vasco" y "local» y qué no (Vaczi, 2015). En

Castillo (2007) sugiere, de hecho, que una forma de evitar semejantes críticas sería concederle al Athletic una denominación de origen al estilo de los productos locales, algo así como un Eusko Label. 
Bilbao, un nuevo fichaje es siempre más que un fichaje; puede llegar a ser un acto simbólico de re-territorialización nacional.

"Para mí el Athletic significa algo que ya casi no se puede encontrar en el mundo", me dijo un aficionado. Y sigue: «Es la Resistencia por excelencia, un símbolo que se alza contra las corrientes del mundo. Un club que insiste en una de las hermosas tradiciones de la historia del fútbol, si no la más hermosa de todas: en él solo juegan jugadores locales». Esta definición resume lo que la mayoría considera la esencia de la marca del Athletic: una cultura futbolística definida por la diferencia. Un titular de la primera página del prestigioso diario deportivo francés L'Equipe de los años setenta indicaba: «El Athletic, un caso único en el mundo del fútbol». Ese titular se convirtió en el credo del excepcionalismo vasco y en una seña de distinción. "Nuestra filosofía no nos hace mejores ni peores», suelen decir en Bilbao; "Somos diferentes».

Este factor diferencial, sin embargo, tiene otra condición que le da sentido: que el Athletic juegue en la primera división. El club nunca ha bajado a segunda. Existe un chiste recurrente en Bilbao con el que los aficionados del Athletic se burlan de sus rivales de la Real Sociedad durante los derbis: "¿Cuál es el título que la Real Sociedad tiene y que el Athletic no, y nunca tendrá?»; la respuesta es: "¡Campeón de la segunda división!». Pero hubo una temporada en que ese chiste fue repitiéndose cada vez menos, hasta que al final dejó de oírse. La abominable perspectiva de descender a segunda división se hizo real. Los bilbaínos nunca olvidarán la fecha del 17 de junio de 2007, el día del «Partido de la Salvación» contra el Levante. En ese último partido de la temporada, el Athletic se jugaba a todo o nada su estatus de primera división. Su filosofía de autosuficiencia y su orgulloso excepcionalismo se enfrentaban al reto definitivo, y la identidad de la ciudad se hallaba en juego.

Este artículo aborda los impases y ansiedades de esa situación en el proceso de identificación y presenta a la comunidad del Athletic Club como si esta se tratara de lo que Turner denominó "una comunidad de sufrimiento» (1969: 14). En el corazón del aficionado reside un compromiso: el de apoyar a un equipo y nunca abandonarlo. En tal compromiso se halla codificada una forma de violencia, ya que se trata de una atadura. Por qué la gente es seguidora de un determinado club deportivo se ha atribuido a factores diversos, como la autorrealización comunitaria, la tradición, la socialización en valores, la evasión de la vida cotidiana o el disfrute colectivo. En Bilbao existe otro factor que liga a los aficionados a su equipo: una doble traba tipo Trampa-22, cuya lógica no reside en lo que atrae a las personas a aficionarse al deporte, sino más bien en lo que les impide abandonar tal afición.

En términos formales, ¿qué es una situación tipo Trampa-22? En su clásica novela satírica sobre la Segunda Guerra Mundial, el escritor Joseph Heller (1961) la define como una lógica circular de la que no existe salida. La Trampa-22 es una oscura norma militar referida a la práctica de los bombardeos aéreos, la cual reconocía que la preocupación por la seguridad personal a la hora de enfrentarse al peligro es un proceso natural de una mente racional, y estipula que una persona puede ser eximida de servir en el ejército a causa de su falta de cordura. Un piloto de bombardero, escribe Heller, podía quedarse en tierra si estaba loco. Todo lo que necesitaba hacer era pedir quedarse en tierra. Pero en cuanto lo hacía, ya no se podía seguir considerando loco, y debía seguir llevando a cabo misiones. La Trampa-22 del piloto es que estaría loco si siguiera volando en misiones, y cuerdo si no lo hiciera, pero si estuviera cuerdo tendría que seguir volando (ibídem: 56). La Trampa-22 es, por lo tanto, una lógica circular que impide a cualquiera eludir una misión de combate; es una situación en la que la 
única solución al problema queda negada por una circunstancia inherente al problema, o por una regla.

La Trampa-22 de Bilbao concierne los dos principios fundamentales de la identidad del Athletic: su filosofía centenaria de jugar solo con vascos, y su permanencia ininterrumpida en la primera división. Cuando en las temporadas 2005/2006 y 2006/2007 ambos principios parecieron ser mutuamente excluyentes, la comunidad del Athletic se vio en un agónico impase acerca de su identidad del que no había una salida clara. Al constituir una trampa formada por requisitos contradictorios, tiene ecos de la teoría de dobles vínculos (double binds) de Gregory Bateson (1973), la cual es aplicable a las misiones de combate metafóricas que se llevan a cabo en el campo de fútbol. Los aficionados, los jugadores y los directivos fueron víctimas de la doble traba de la filosofía de solo vascos.

Este artículo es parte de un estudio etnográfico más extenso que llevé a cabo en Bilbao durante los años 2009-2011 para mi tesis doctoral (2013), y forma parte del libro que publiqué a continuación sobre las dimensiones sociales, políticas y culturales del Athletic Club (Vaczi, 2015). Se basa en 18 meses de trabajo de campo en Bilbao y el País Vasco, así como en más de cien horas de entrevistas en profundidad con aficionados, jugadores, entrenadores y directivos del club. En primer lugar, examinare dos meta-relatos que han tenido un peso especial en la construcción de la identidad que denomino el excepcionalismo vasco: el discurso antropológico que creó una imagen particular de los vascos como categoría social, cultural, étnica y racial (Zulaika, 1996), y el discurso político que se ha servido de relatos científicos para sus fines ideológicos-políticos (MacClancy, 1993). La noción de diferencia ocupa un lugar central en ambos relatos, creando un imaginario, motivo de amplio debate pero que, no obstante, ha tenido consecuencias en el modo en cómo los vascos se ven a sí mismos. Segundo, examinaré cómo estas narrativas de la identidad se reflejan en la filosofía especial del Athletic Club, y terminaré por identificar los impasses de identidad de tipo Trampa-22 que pueden producir esos discursos.

\section{NOS HAN DICHO QUE ÉRAMOS DIFERENTES}

«Si, tal como proclaman los carteles turísticos, «España es diferente», escribe el antropólogo Jeremy MacClancy, "entonces los vascos son muy diferentes» (1993: 92). Los medios de comunicación populares a menudo presentan a los vascos como un pueblo antiguo, hosco y misterioso que habita en los Pirineos. Un episodio de la célebre serie de documentales de viajes Orson Welles around the world (1955) arranca con una panorámica de los montes Pirineos, en la frontera franco-española. Welles, uno de los más conocidos cineastas de su época, describe el País Vasco como un "rincón muy apartado" y "poco conocido" de Europa, y la frontera "más como un concepto teórico" que como un hecho, un concepto teórico propuesto por el gobierno francés y el español. ¿Pero quiénes son los vascos? «Nadie lo sabe realmente -afirma Welles-, aunque sí sabemos quiénes no son: los vascos no son franceses ni españoles, ni mediterráneos, ni alpinos, ni magiares, ni celtas, ni germanos, ni semíticos, ni escandinavos, ni siquiera arios ${ }^{2}$. Welles describe a los vascos como insulares y distantes, mis-

2 Documental disponible en: https://www.youtube.com/watch?v=hJIKx3NPuts. Última consulta: 11/01/2020. 
teriosos e incomprensibles, desafiantes y subversivos, "diferentes» y auténticos, habiendo evolucionado in situ desde el origen de los tiempos al igual que los «Red Indians» de América. Tales representaciones muestran a los vascos como un pueblo singular cuyo carácter diferente reposa sobre dos pilares: en una definición en términos de quiénes no son, y en la reivindicación de unos vínculos ancestrales con su tierra que parten de tiempos prehistóricos.

Los vascos son un pueblo muy investigado por la antropología (Zulaika, 1996). Al canalizar la atención de los científicos hacia la evolución y la categorización de las especies, el cambio de paradigma que supuso el darwinismo tuvo consecuencias en la consolidación de la craneología y de la antropología física. Los vascos se convirtieron rápidamente en motivo de curiosidad en todo el mundo. El primer científico importante que se ocupó de medirlos fue el suizo Anders Retzius, profesor de anatomía y miembro de la Real Academia de las Ciencias Suiza (Zulaika, 1996: 50). El francés Paul Broca, antropólogo y fundador de la Sociedad de Antropología de París y de la Revue d'Anthropologie, estudió sesenta cráneos de vascos, exhumados de manera furtiva en Gipuzkoa. El británico A. C. Haddon, del Instituto Londinense de Antropología, estudió la prehistoria vasca y propuso que los vascos eran descendientes directos del Cro-Magnon. El antropólogo local que encabezó la investigación sobre los vascos fue Telesforo de Aranzadi, fundador de la Sociedad para los Estudios Vascos (Eusko Ikaskuntza). Aranzadi defendió la primera tesis doctoral en antropología en España en 1889, con el título El pueblo euskalduna, en la que resumió la evolución y la teoría racial de los vascos, vinculándolas a investigaciones europeas (MacClancy, 1993: 99-103). Sintomáticas del entusiasmo que rodeaba la investigación sobre los vascos fueron las palabras de R. Collignon, quien, tras trabajar en 1893 con cráneos provenientes de la provincia de Gipuzkoa, dijo: "Ante mis ojos se revelaba un tipo de hombre nuevo, profundamente distinto, no solamente de todos los que, en las mismas condiciones, había observado en Francia, sino también de todos aquellos que yo había estudiado en el Norte de África» (apud Zulaika, 1996: 53).

Continuando esta investigación fundacional, en las décadas que siguieron, una distinguida serie de arqueólogos, lingüistas, folcloristas y antropólogos culturales mostró a los vascos acompañados de prefijos como no-, pre- y proto-. Los vascos se presentaron así ante el mundo como un pueblo que precedía a todos los demás de su área geográfica, que hablaba una lengua no indoeuropea (Humboldt, 1821), cuyas costumbres, tradiciones (Gallop, 1970) y relaciones de género (Ortiz-Osés y Mayr, 1980) eran diferentes a las de sus vecinos, y cuya antiguas estructura política y sistema de toma de decisiones constituían la primera protodemocracia (Baroja, 2009). Estas definiciones «impuestas» (MacClancy, 1993: 117) por la comunidad científica construyeron la raza y la cultura vascas como distintas y provistas de un origen local. Muchas de estas teorías han sido puestas en duda o rebatidas por la ciencia moderna, incluyendo la distinción étnica y racial y la evolución autóctona. Lo relevante para nuestros propósitos, sin embargo, no es tanto el valor real de tales discursos como sus consecuencias en las identidades social, cultural y política. Cierto o no, un discurso genera una cierta realidad.

"¿Cómo sabe usted que es india?», se le preguntó a una joven Mashpee en 1976, en un juicio en Massachusetts, en el cual los Mashpee debian demostrar que eran una tribu antes de poder reclamar la posesión de sus tierras, y donde participaron antropólogos como expertos. "Mi madre me lo dijo" (Clifford, 1988: 301). Otro miembro de la tribu declaró: "Somos diferentes. Sabíamos que éramos diferentes. Nos han dicho que éramos diferentes [los antepasados y los antropólogos]» (ibídem: 281. El poder legitimador del discurso científico es tal que puede construir identidades colectivas. Se espera de los científicos que den un testimonio experto, 
que digan a la gente quién es, que legitimen su «tribu». Para la pregunta de cómo los vascos saben que lo son, la respuesta puede ser la misma: «Me lo dijo mi antropólogo». El mero interés científico en un pueblo basta para comunicar a este una impresión de singularidad. Durante mi trabajo de campo, me pidieron repetidamente que explicara por qué había venido a Bilbao cuando podría haberme centrado en los grandes: el FC Barcelona o el Real Madrid, más populares y poderosos. "¿Por qué nos ha elegido a nosotros?», preguntaban. La única respuesta posible que podía darme a mí misma (y a la agencia que me proveía de fondos) para legitimar mi investigación era: «Porque el Athletic es diferente». Históricamente, escribe MacClancy, que los antropólogos se molesten en «invertir su tiempo en investigar la prehistoria vasca (en lugar de, por ejemplo, la española), ayudó, y ayuda, a los nacionalistas comprometidos a justificar la elevada consideración que tienen de su propio pueblo» (1993: 114). Las diferencias étnicas, biológicas, culturales y lingüísticas (Urla, 1993, 1995) establecidas por la ciencia se convirtieron en elementos básicos en el discurso político vasco del excepcionalismo.

\section{NI ESPAÑA, NI FRANCIA}

Mucho antes de que el movimiento nacionalista vasco cristalizara a finales del siglo diecinueve en su forma moderna, un sentimiento de diferencia caracterizaba ya a los pueblos del norte de España. Este sentimiento de diferencia surgía de dos fuentes principales: la noción de hidalguía colectiva y los fueros.

Las raíces de la hidalguía colectiva se remontan al año 1053, cuando a los habitantes de un valle se les concedió permiso para formar su propia milicia (Conversi, 1997: 178). Posteriores reyes católicos otorgaron el título de hidalguía colectiva a las provincias vascas de Bizkaia y Gipuzkoa a cambio de ocuparse de la defensa de su frontera: «todo hombre capaz de demostrar que sus padres eran vascos (...) era reconocido automáticamente como hidalgo en virtud de su pureza de sangre» (Greenwood, 1977: 86). La hidalguía colectiva se convirtió en el «núcleo moral del sentimiento de singularidad vasco" (ibídem: 86). Los fueros se codificaron en los siglos diecisiete y dieciocho entre la Corona española y los poderes regionales vascos, eximían a los locales del servicio militar así como del pago de impuestos, y permitían a las asambleas provinciales el veto de edictos reales. Era este un privilegio considerable, que los vascos lograron conservar hasta 1876, durante más tiempo que otras regiones como, por ejemplo, Cataluña. La pérdida de los fueros, símbolo e instrumento de la independencia económica y regional, fue un factor decisivo en el surgimiento del nacionalismo a finales del siglo diecinueve (Payne, 1975). Tanto la hidalguía colectiva como los fueros generaron en los vascos la impresión de ser agentes políticos diferenciados dentro del Estado español.

El discurso nacionalista vasco nació de Sabino Arana Goiri a finales del siglo diecinueve, y enfatizaba las distinciones étnicas y de raza como valores fundamentales. En el discurso de Arana resuena el discurso de diferencia científico y popular. Arana creó la ideología y el simbolismo nacionalistas, así como el Partido Nacionalista Vasco. Su conceptualización de la identidad era primordial, esencialista y basada en el nacimiento: para Arana, la mejor prueba de la pureza de sangre vasca era tener ocho apellidos vascos ${ }^{3}$.

3 Arana difundió su ideario en su revista Bizkaitarra entre 1893-1895. 
Con el surgimiento de ETA en 1959, vemos una redefinición de las bases de identidad del nacionalismo vasco: un giro de conceptualizaciones primordiales, basadas en la sangre, hacia otras performativas, basadas en la acción y en la clase social. Tratándose de una organización marxista que simpatizaba con la clase trabajadora, ETA se propagó entre los emigrantes de clase trabajadora provenientes del resto de España. "Consideramos a los emigrantes y a sus hijos más vascos que esos capitalistas con largos apellidos vascos que se atreven a llamarse patriotas mientras no cesan de enriquecerse a costa de su propio pueblo" (apud MacClancy, 1993: 105). El nacionalismo abertzale abrazó a las clases trabajadoras y no era étnicamente exclusivo (Kasmir, 2002). En lugar de la raza vasca, el nacionalismo vasco de izquierda enfatizaba el pueblo trabajador vasco (MacClancy, 1993: 107), que ETA consideraba explotado. ETA veía la acción como el sello distintivo de la identidad vasca, la cual era por naturaleza una identidad política: ser vasco era ser abertzale, un activista nacionalista pro-independencia vasca, un simpatizante y un militante de la causa vasca. "No naces abertzale», escribe MacClancy (ibídem). "Te haces aberzale» (ibídem). Heilberg afirma que ETA redefinió la comunidad moral. "Cualquiera que apoyara la causa vasca formaba parte del "nosotros" $y$, al margen de la genealogía, los que no la apoyaran eran los "otros"» (1980: 50).

Los discursos antropológico y político han sido constructores muy influyentes de la identidad vasca, y su sine qua non fue el énfasis en la diferencia étnica, lingüística y cultural, así como en la pertenencia indígena a la tierra. La filosofía de fichajes localista del Athletic alberga funciones discursivas y performativas de similar importancia.

\section{DE SANTIMAMIÑNE A SAN MAMÉS: FÚTBOL Y LA FANTASİA DE LOS ORÍGENES}

En 1916, un grupo de escolares descubrió en las cercanías de Basondo, en la provincia de Bizkaia, una cueva que albergaba curiosas pinturas rupestres. La caverna del Paleolítico Superior se convirtió en un icono cultural y en eje central de identificación para el imaginario cultural vasco: evoca ascendencia local, evolución ininterrumpida, indigenismo e insularidad para la cultura tradicional vasca. Para los vascos, fue una prueba de lo que los antropólogos les habían contado sobre su prehistoria e identidad: la cueva era el contexto tangible en el que su pasado imaginado se hacía realidad (Zulaika, 1988: 7).

Llamaron a la cueva Santimamiñe, el nombre vasco de una ermita vecina, conocida en castellano como San Mamés. El lugar se convirtió en tocayo del estadio del Athletic Club, construido tres años antes al lado de otra ermita dedicada al mismo santo. San Mamés es donde los ecos de Santimamiñe y las pasiones más firmes y duraderas de la ciudad se convierten en evento. En cierto sentido, el estadio de San Mamés es el equivalente alegórico de la cueva de Santimamiñe: ambos son un espacio para el deseo, la identificación y las raíces. Son la afirmación vasca de pertenencia indígena al territorio, a una red familiar, a una nítida conciencia de diferenciación. En la tradición futbolística de San Mamés resuenan el Santimamiñe prehistórico y el discurso antropológico: desarrollo local, indígena, y un establecimiento étnico de límites basado en el énfasis en la diferencia.

Los aficionados de Bilbao creen que los jugadores son más eficientes si de veras aman su club, y el mejor modo de asegurar tal amor es mediante una formación local y a largo plazo 
del jugador como persona y deportista. También creen que esa dedicación resulta en un rendimiento superior, por lo cual la cantera local es, de hecho, fuente de fortaleza y no debilidad. La confianza en los recursos locales, su explotación al máximo mediante el trabajo duro y la autosuficiencia resultante son valores constituyentes del con frecuencia citado "orgullo vasco». Es habitual que un jugador inicie su carrera en el Athletic y la concluya alli, tras haber jugado cientos de partidos con el único club de su vida. En un sentido primordial, el jugador del Athletic encarna el indigenismo vasco: el constituye un vínculo ininterrumpido con los origenes. "Nace» en la comunidad literal y figuradamente, y se desarrolla en la misma. Es producto de la tierra, de las cavernas, de la cantera.

Por lo tanto, la filosofía del Athletic de solo vascos es lo que Laplanche y Pontalis (1986) Ilamarían una fantasía fundamental que trata de responder el «enigma de los orígenes». La cultura futbolística constituye una narrativa de fantasía que «mediante las ficciones de mitos personales se interroga sobre los orígenes: ¿De dónde procedo? ¿Por qué y respondiendo a qué intención estoy aquí?» (ibídem: 34). El Athletic responde a un enigma que ha sido una preocupación particular de la antropología vasca y europea, así como determinante para la identidad y la política vascas. A través del Athletic, es aún posible ser testigo directo de los orígenes propios en Santimamiñe-San Mamés y en la cantera. El bucle temporal de fantasía, la creencia en que el Athletic representa un vínculo ininterrumpido con sus orígenes permite a los aficionados presenciar, con cada nuevo jugador salido de la cantera, el comienzo imaginario de su comunidad.

"¿Qué sería nuestro Athletic sin su pasado?» se preguntaba Alejandro de la Sota ya en 1932 (ibídem: 257). Solo cuarenta y cuatro años tras su fundación, el club ya se definía por su pasado. Y realmente, ¿qué sería el Athletic sin él? En cierto sentido, la "tradición centenaria» del club se «inventa» de manera retrospectiva, por emplear el concepto de Hobsbawm y Ranger (1992), como un modelo cuyas funciones simbólicas son la invariabilidad y el establecimiento de una continuidad con el pasado que resulte apta para el presente. No es la tradición per se lo que se inventa; más bien, lo que se proyecta de manera retrospectiva es una sensación de continuidad e invariabilidad. Tales proyecciones, afirman Hobsbawm y Ranger, son «respuestas a situaciones inéditas que adoptan la forma de referencias para situaciones antiguas» (ibídem: 1). Su necesidad reside en el "contraste entre el cambio constante y las innovaciones del mundo moderno y el intento de estructurar como continuas e invariables al menos ciertas partes de la vida social que forma parte de ese mundo moderno" (ibídem: 2). El Athletic y su política de fichajes son precisamente tal intento: ante los cambios sociales, culturales y políticos de Bilbao, es celebrada como el único fenómeno que se resiste a ellos.

\section{4. ¿QUÉ ES UN BERTSOLARI PARA ZIDANE? LOS ASTERIX Y OBELIX DEL FÚTBOL GLOBAL}

La bertsolaria o poesía improvisada es la más famosa manifestación cultural de la lengua vasca. Se lleva a cabo en un entorno competitivo: cinco o seis bertsolaris se disponen formando una línea, el público les da una palabra o un tema y ellos, ciñéndose a una rima, un metro y una melodía fijos, deben improvisar y cantar sobre aquella palabra o tema. La bertsolaria se considera una práctica genuinamente vasca, y a sus practicantes los mayores maes- 
tros de una lengua en peligro. Simboliza una cultura rural tradicional que sobrevivió en los pueblos y en las casas de campo durante la prohibición del euskera en el contexto del régimen de Franco.

Como finalistas del Campeonato Nacional de Bertsolari de 2005, el poeta Jon Maia y sus rivales fueron invitados a San Mamés a asistir un partido contra el Real Madrid. Como representantes de la más íntima cultura popular, la presencia de aquellos poetas plasmaba la disonancia e incongruencia del Athletic en una cultura deportiva globalizada. "En los minutos que anteceden al partido», recuerda Maia,

«estábamos en los túneles de acceso a los vestuarios. A un lado, Guerrero, Gurpegi, Lacruz, Urzaiz y compañía. Al otro, Casillas, Roberto Carlos, Zidane... recuerdo que aquel día no estuvo Beckham. Y entre aquellas dos filas de estrellas, nosotros, los ocho bertsolaris. Andoni hizo el saque de honor y, si no recuerdo mal, canto un bertso desde la mitad del campo. ¿Que pensarian aquellos jugadores de nosotros? A saber, seguramente nada. ¿Qué es un berstolari para Zidane? Solo plantearse la pregunta... [Más tarde en el palco VIP] en torno de un canapé, el todopoderoso hombre de negocios estatal, con voz y voto en los centros de poder de la política de Estado, y el bertsolari de Hendaia, procedente de la realidad vasca mas cruda.» (2013: 178-179)

El Athletic ocupa una posición única como espacio de encuentro entre mundos muy diferentes y entre relatos polifónicos: al posibilitar la intersección de lo local, lo nacional y lo global, acentúa cada uno de tales ámbitos. Compitiendo en primera división, el Athletic proporciona un lugar que permite que la "diferencia» del indigenismo, la cultura y la identidad local sobresalga del contexto global.

Si los antropólogos construyeron a los vascos como los «nativos de Europa», no resulta sorprendente que el Athletic se conceptualice como los «Asterix y Obelix» del fútbol español y del internacional: los locales indomables, los galos que se resisten a la ocupación romana. En su libro sobre la gestión del fútbol de élite, el antiguo directivo del FC Barcelona Ferrán Soriano distingue entre varias estrategias de gestión. Está el modelo galáctico seguido por gigantes como el Real Madrid y el FC Barcelona, que lucha por adquirir a los mejores jugadores del mundo y por ganar títulos internacionales. Los hay que aspiran razonablemente a ganar títulos nacionales y que juegan un papel modesto en los campeonatos internacionales. Y luego está el Athletic Club de Bilbao. El antiguo jugador Andoni Zubizarreta lo expresa del siguiente modo: "Somos antiglobalización. Hay mucha gente a la que no le gusta la gran escala ni la carrera de locos para hacer dinero. La imagen del pueblo lleno de galos que luchan contra un enemigo poderosos nos resulta atractiva» (apud Soriano, 2012: 37).

\section{LA TRAMPA-22 DE BILBAO: EL PARTIDO DE LA SALVACIÓN}

Al cabo de dos agónicas temporadas en la zona de descenso, en 2007, el Athletic se vio a un partido de abandonar la categoría de primera división. Surgió entonces la pregunta: ¿Debería el club mantener su principio de fichajes localista, cuando este está fracasando de manera tan estrepitosa? Algunos seguían defendiendo tal filosofía, pero para muchos otros, 
esto resultó no ser solo una mera cuestión de gestión sino una insoportable doble traba en la que se hallaba en juego la esencia del club. Si abandonamos nuestra filosofía de fichajes localista, razonaban los bilbaínos, ya no somos un «caso único en el mundo del fútbol». Pero si la conservamos, podemos bajar a segunda división, donde una plantilla de solo vascos ya no es algo único. En cualquiera de los casos, uno de los principios fundamentales de identidad se perdería, y quedaría rota una tradición centenaria. Los dos requisitos básicos, y negativos, de la identidad del Athletic («no fichar a extranjeros» y "no perder el estatus de primera división») entraban en conflicto entre sí: competir con jugadores locales y hacerlo en primera división parecía irreconciliable. Lo que acababa de establecer la doble traba y cerrar la Trampa-22 era un tercer requisito negativo: no abandonar la misión. No abandonar a un equipo de jugadores nacidos en casa, «nuestros chavales de la tierra». Los efectos de la doble traba fueron violentos psicológicamente, y aun así los aficionados del Athletic siguieron asistiendo al estadio. De hecho, cuanto más desesperada se volvía la situación, más imperativo era llenar San Mamés.

Aquella temporada quedó registrada en la historia del Athletic como el "Annus Horribilis». Corrían tiempos apocalípticos: el Athletic se encontraba «a un solo paso del abismo» (Deia), se jugaba "109 años de historia» (El Mundo), y «un mito se hallaba en peligro» (Deia). Los bilbaínos se pasaron las últimas semanas de la temporada haciendo cálculos de probabilidades, escrutando interminables combinaciones de victorias, empates y derrotas entre los cuatro equipos que se hallaban en la zona de descenso o próximos a ella. Entre los titulares alarmistas asomó, tímidamente, un inquietante Nuevo Mundo: «El 21 de junio, un sexto candidato a la presidencia [las elecciones para la presidencia del Athletic se celebrarian pocas semanas después] se presentará de manera oficial a las elecciones del club. Está a favor de contratar a extranjeros» (Gara). ¿Se acercaba el fin de una cultura futbolística de renombre mundial? El responsable de Relaciones Exteriores del club me dijo que recibieron miles de cartas y de llamadas telefónicas durante los últimos meses de la temporada. Me permitió leer los archivos: cartas enojadas, desesperadas e implorantes. Todas mostraban el mismo padecimiento fruto del miedo y la vulnerabilidad. "Esta temporada es pura angustia, frustración y sufrimiento", escribe una anciana con letra temblorosa. Y continua: "Si bajamos a segunda, ya no seremos un caso único en el mundo del fútbol». "Querido club», escribe un anciano, "los aficionados que van a San Mamés están sufriendo una gran impotencia. ¿Qué puedo hacer?» Otra carta manuscrita, de veinte páginas de extensión, ofrece una estrategia para «marcar por fin un gol, por amor de Dios». Otra solicita una mayor vigilancia de los jugadores y el establecimiento de toque de queda para los mismos.

Bilbao era una ciudad al borde del desastre. "El Athletic era el único tema en casa, no de las conversaciones sino de los silencios en que hablábamos con los ojos», me dijo un aficionado. Este mismo relataba: «Nadie decía nada, pero solo con mirarnos entre nosotros, mi madre, mi padre y mi abuelo, ya lo decíamos todo. Fue la única vez en que no hablamos del Athletic en casa. ¿Miedo? ¿Bajón? No lo sé». Otros se abandonaban a la conmiseración y a las distracciones sociales para mantener aquel terrible silencio a raya. Las conversaciones en las calles y en los bares versaban sobre una única preocupación. «¡Vamos a bajar!»; «¡Pinta muy mal!»; "Quiero que acabe esta temporada, esto es un sinvivir». Los días previos al Partido de la Salvación, una delegación convocada por la Peña de Deusto, un barrio bilbaíno, realizó una peregrinación a la basílica de la virgen de Begoña, la patrona de la ciudad. Fueron muchos los que se sumaron a la subida ritual de las escalinatas que arrancan de la plaza de Unamuno y conducen a la basílica, para rezar a la virgen por la salvación del Athletic. 
El estadio se llenaría hasta la última butaca, como de costumbre, pero muchos pensaron que no serían capaces de soportar la presión y prefirieron aislarse. No obstante, aquel día era imposible esconderse del fútbol. Como me contó un aficionado:

Yo había visto temporadas de todo tipo, pero aquello era demasiado. No podía ver el partido. Dejé mi pase de temporada a un amigo y decidí ir a pescar al rincón más alejado de la provincia. Al principio todo fue bien, hasta que apareció un inspector que quiso comprobar mi licencia de pesca. «iQué raro que alguien venga hoy a pescar! ¿No le gusta el fútbol?», preguntó. "Sí - dije suspirando-, por eso estoy aquí». Para colmo, el inspector era un antiguo jugador del Athletic, y estaba perfectamente informado de la marcha del partido: 0-0.

\section{Otro aficionado recuerda:}

Me sentía mal, muy mal. Tanto que no quise ir al partido. Hacía un día sofocante. Cogí la bici y fui a dar una vuelta por los caminos más desiertos posibles. Quería aislarme del mundo un par de horas. De pronto, el móvil me empezó a vibrar en el bolsillo. Una llamada perdida de un amigo. Se me paró el corazón. Quise pensar que era un gol, pero preferí no pensar nada y seguí en mi mundo paralelo de calor, sudor y pedales. Poco después, otra llamada perdida... y me puse a pedalear como un loco de vuelta a casa. Encendí la tele, la radio, el ordenador, todo a la vez.

Por su parte, a los jugadores les aterrorizaba ser la plantilla que arruinara una tradición centenaria. "El equipo iba literalmente de puntillas aquella temporada», me dijo el medio campo Gurpegi. «En una ciudad donde el futbolista vive, relativamente, la misma vida que cualquier otro joven, aquella temporada evitábamos salir a la calle para que la gente no pensara que éramos poco profesionales». El zaguero Ustaritz me habló de los momentos previos al partido vividos en el vestuario. «Estábamos aterrorizados. Uno de nosotros intentó romper el hielo e hizo un chiste: "Si perdemos este partido será mejor que cavemos un túnel desde este vestuario hasta el aeropuerto y desaparezcamos de esta ciudad para siempre". Pero no tuvo gracia. Era imposible perder y seguir en Bilbao». Los directivos del club sentían lo mismo. "No me puedo imaginar ser directivo de un equipo que pierde su puesto en primera división y seguir en Bilbao. Sería imposible vivir soportando la decepción de toda la ciudad», confesó un antiguo directivo del club. Ana Urquijo, quien era la presidenta por aquel entonces, me dijo: "Si hubiéramos perdido y bajado a segunda división, hasta mis futuros nietos se habrian visto afectados. La gente diría: "¡Mira, esos son los nietos de la presidenta que hizo bajar al Athletic a segunda!"».

La historia del Athletic, como escribió Alejandro de la Sota en 1932, «no alcanzará vuelos netamente románticos hasta que el club baje a la segunda división y jeup! vuelva a subir a la primera» (1932: 294). Hay que ser de Bilbao para conocer como es debido el espectro demoníaco de tal "vuelo romántico». Para los bilbaínos, aquella calurosa tarde de junio, en San Mamés, se manifestó el lado más monstruoso del fútbol.

«El calor era sofocante», recuerda un aficionado:

Tuvimos unas pocas ocasiones en la primera parte, pero sin llegar a marcar. Llegamos 0-0 al descanso. Pese al calor húmedo, yo tenía sudores fríos, estaba pálido y mudo. Al menos llegaban buenas noticias de otros estadios. Competíamos, entre otros, con el Celta de Vigo por la primera división. Eso ayudó mucho; durante aquellos malditos noventa minutos, no pasamos ni un segundo en segunda división. 
Pero un gol del Celta habría creado demasiada presión. Durante el descanso no fui capaz de intercambiar palabra con nadie. Fumé dos paquetes de cigarrillos. Seguía teniendo sudores fríos y un dolor de cabeza brutal, y continué más o menos igual cuando empezó la segunda parte. Un montón de oportunidades, pero Molina [el portero rival] lo paraba todo. Alrededor del minuto sesenta llegó el primer igoool! Salté como un loco, todo el estadio se puso frenético, y sentí que me quitaban un enorme peso de encima. No creo que hayamos celebrado nunca un gol como lo hicimos con aquél. Pero aún no había acabado, y entonces igoool! Gabilondo marca el 2-0. Sentí que me seguían quitando peso de encima, me sentí cien kilos más ligero. Por fin, el árbitro pitó el final del partido. Miré alrededor y vi a la gente llorar de alivio. Todo San Mamés estaba llorando. Abracé a mis vecinos, me senté y me fumé un último cigarrillo. Por fin había terminado. Todavía en estado de shock, salí en silencio del estadio deseando no tener que volver a pasar nunca por un drama así.

\section{6. ¿SOMOS DISTINTOS O ESTAMOS LOCOS?}

De cuando en cuando, el club pasa por una crisis, mayor o menor, a causa de su filosofía de fichajes. Cada vez que se cuestiona la eficacia de tal filosofía, Bilbao se sumerge en la introspección. En 2012, la Asamblea General del club organizó una mesa redonda bajo el título: "¿Somos distintos o estamos locos?" (Capetillo, 2012). De cuando en cuando, la cuestión surge en Bilbao: ¿Somos héroes románticos, o solo tontos románticos?

El Athletic Club es un ideal anacrónico que planta cara a un mundo postmoderno. Según Richard Giulianotti (1999: 33), pese a la tendencia general hacia una afición futbolística globalizada y descentralizada, seguimos encontrando a nivel de club importantes reflejos de periodo industrial, urbano y en los comienzos de la modernidad en que el fútbol surgió como deporte nacional. El Athletic es uno de tales reflejos. Es el último de su clase, una rareza representativa de una antigua línea aristocrática y que se enfrenta ahora a la postmodernidad. El pathos y el sufrimiento del club en un mundo que le es ajeno genera la paradoja central de la afición del Athletic: cualidades como la inocencia, la humildad y la flaqueza pueden ser en realidad una fuente de fortaleza. Se trata de una combinación contradictoria de incapacidad y de una suerte de santidad, que da lugar a lo que Bakhtin denominaría una personalidad "umbral»: una interfaz entre la realidad y un abismo que amenaza con aniquilar la identidad del sujeto (apud Halliwell, 2004: 83).

La estrecha línea entre el héroe romántico y el tonto es palpable en Bilbao. Para muchos, el atavismo de la filosofía del Athletic ha rozado a menudo el ridículo. La temporada 2006/2007 reveló los impases de la fijación del club con los jugadores vascos en un mundo futbolístico multi-nacional. El ansia por hallar jugadores vascos llevó al club, repetidamente, a ampliar, restructurar y reformular el significado de "local» y "vasco». La filosofía se fue definiendo en términos cada vez más laxos con el fin de poder escoger entre un abanico más amplio de jugadores. Tras las miserias del Partido de la Salvación, el Athletic rondó a dos jugadores: Kepa y Jorge López. El único vínculo vasco de Kepa era su madre, de Cruces; el de Jorge López, un abuelo de Sestao, ambas, localidades vecinas de Bilbao. No habían nacido en el País Vasco, ni vivido nunca allí. Surgió la pregunta: ¿Son vascos? ¿Pueden jugar en el Athletic?

La posibilidad de que Kepa y Jorge López fueran aceptados como vascos y por tanto considerados aptos para el equipo les pareció ridícula a muchos aficionados. La temporada 
2006/2007 generó un debate público acerca de la filosofía del Athletic, y fueron muchos quienes señalaron el bochorno que podía acarrear al club. Como el antiguo miembro de la junta del Athletic Club Fernando Astorqui dijo:

«Si para mantener la filosofía tenemos que empezar a mirar si un jugador de Málaga tiene una abuela o una prima en Galdakao, o si uno de Logroño tiene un pariente en Sestao de toda la vida, yo creo que es mejor plantarse y dejarlo porque eso es hacer el ridículo.» (apud Agiriano, 2007a)

Otro comentarista publicó una breve historia de la evolución de la filosofía del Athletic, señalando que, con el paso del tiempo, se ha ido abriendo más y más a jugadores no nacidos en el País Vasco con el fin de "superar la tentación de seguir un criterio etnicista que solo conduce al ridículo" (apud Agiriano, 2007b). La búsqueda del vínculo vasco, daban a entender los críticos, adopta en ocasiones proporciones ridículas, como evidencia el tono sarcástico del siguiente comentario:

"Sería posible la contratación de georgianos, basada en la presunta relación del euskera con las lenguas caucásicas, de marroquíes que casualmente pasaron por Gernika; muchachotes de Terranova o de Saint Pierre et Miquelon podrían reforzar nuestra defensa, bajo el museístico paraguas de la pesca de la ballena; se podrá contar con indochinos de ascendencia vascofrancesa o vascofranceses de origen indochino.» (Ugarte, 2007)

Para muchos, los argumentos empleados para redefinir quién es aceptable como vasco se estaban volviendo cada vez más "arduos», "complicados» o simplemente "cómicos».

De pronto, la filosofía de fichajes resultaba vergonzosa por otro motivo: la arrogancia de llamarla una "filosofía», cuando ahora más parecía una carga en forma de ideología. El comentario de un lector en el periódico local Deia recordaba a los aficionados que, semánticamente, filosofía significa "amor al conocimiento», así como la búsqueda sistemática de la razón última de las cosas. "Con tanta filosofía aqui y allá», escribió Pedro Ugarte, "esto parece el Aerópago de Atenas y los bebedores que crecen a lo ancho, en las tabernas cercanas a San Mamés, una caterva de metafísicos del fútbol» (2007). Otros daban a entender que la así Ilamada filosofía había elevado al Athletic a «cotas metafísicas» que poco tenían que ver con la realidad. El himno actual, escrito en los años ochenta del siglo veinte, apenas hace mención a Bilbao. En su lugar, enumera los ingredientes de un imaginario nacionalista vasco. Está escrito en euskera, pese a ser esta una lengua que apenas se emplea en Bilbao. Habla de Euskal Herria, la denominación en euskera para las siete provincias históricas vascas, y de «nobles vascos», mientras que el Athletic fue originalmente un club provincial. Evoca una identidad rural al mencionar el irrintzi, una tradicional forma de comunicación en las montañas, pese a que Bilbao se ha convertido en una ciudad post-Fordista y postmoderna. Muchos estaban de acuerdo en que la filosofía desvinculaba al Athletic de sus realidades, y que ha sumido al club en el autoengaño: ya no es una solución sino una "ratonera ridícula» (Ugarte, 2007). En conclusión, Bilbao afrontaba el dilema de «acabar de una vez por todas con la filosofía del Athletic, si no queremos que ella acabe con nosotros» (Salaburu, 2007).

Los tiempos apocalípticos del Athletic condujeron a los aficionados a una dolorosa revelación: la filosofía de fichajes que tanta satisfacción y orgullo les daba, reportaba asimismo sufrimiento y ridículo. "Es como correr un maratón con un saco de patatas a la espalda», me dijo el antiguo presidente del club Fernando Lamikiz, refiriéndose a la debilitadora carga del 
club. "Si ganas, has hecho algo extraordinario, pese a tu desventaja. Pero si pierdes, se ríen de ti: ¿Quién en sus cabales piensa que se puede ganar un maratón con un saco de patatas a la espalda?» Habiendo llegado a un punto crítico, los aficionados se volvieron conscientes de las incongruencias disfuncionales de su santurrona «filosofía».

\section{TENEMOS QUE PERDER PARA GANAR: EL NARCISISMO DEL MASOQUISMO MORAL}

¿Por qué sigo yendo?, ¿soy masoquista?, ¿es esto lo que quiero de verdad? En el centro de un impase histérico, nos dicen los psicoanalistas, reside un deseo alienado (Žižek, 2006: 38). Un ejemplo de deseo alienado se da cuando, en la sociedad patriarcal, el deseo de una mujer es el resultado de las expectativas masculinas impuestas sobre ella: ella quiere lo que su gran Otro, el hombre, quiere que ella quiera. El impasse histérico surge cuando el sujeto cesa de estar cómodo con la imagen simbólica impuesta sobre ella o él. El Athletic incurre de manera rutinaria en imposiciones de ese tipo. Los aficionados del Athletic experimentan un impasse histérico cuando se percatan de que la identidad simbólica y el deseo que les impone la filosofía vasca quizás no sean la suya. Como me dijo un aficionado: "Yo nací en Bilbao, y no tuve la opción de no seguir al Athletic. Aqui todo el mundo sigue al Athletic, desde hace generaciones». En la provincia de Bizkaia, de modo casi literal, "todos nacemos con pijamas con los colores del Athletic». Un aficionado quiere lo que su familia, su cuadrilla, sus maestros o el cura quieren. Miren adonde miren, ven una devoción cómplice a los mismos colores. La familia, la tradición y la historia se convierten de este modo en el gran Otro del aficionado: él o ella encarna el deseo de aquellos. En épocas de gran sufrimiento, una sensación de alienación sorprende al sujeto: ¿De verdad es esto lo que quiero? ¿De verdad queremos conservar esta antigua tradición, cuando las tradiciones se pueden cambiar o zanjar por completo? ¿Esto de verdad me representa? Las cuestiones, no obstante, son solo retóricas. En el corazón de la afición del Athletic reside una doble traba que no permite a sus actores desertar del terreno de juego. Según Bateson (1972), un doble vínculo implica una "víctima" y una figura de autoridad que impone el doble vínculo. En el caso del Athletic, los aficionados se pueden sentir "victimizados» cuando piensan que no tienen más opción que sufrir por su equipo semana tras semana. "¿Por qué voy si todo lo que hacen es perder?" oí repetidamente. Y, aun así, no pueden dejar de ir porque eso rompería una tradición de varias generaciones apoyando al Athletic.

En una situación de doble traba dos requisitos entran en conflicto. Existe un primer requisito negativo en forma de una prohibición (ibídem: 178), junto con la amenaza de un castigo en caso de no ser obedecido. El primer requisito negativo del Athletic es la obligación de decir "no" a los extranjeros. El programa humorístico de la televisión vasca ETB Vaya semanita hizo en una ocasión una parodia de la religiosidad de la filosofía del Athletic, mostraba una iglesia rojiblanca donde un joven novicio acudía a confesar:

«Bendígame, padre, porque he pecado de pensamientos impuros. Viendo jugar a Messi, he tenido la fantasía de fichar a extranjeros...». "Hijo - dice el sacerdote-, recuerda el primer mandamiento de Clemente: "Bajo ninguna circunstancia ficharás a extranjeros"..1 ${ }^{4}$

4 Disponible en: https://www.youtube.com/watch?v=8JV5hEMnuiw. Última consulta: 11/01/2020. 
El primer requisito del Athletic es ese mandamiento: el tabú de fichar a extranjeros. Si lo haces, ya no eres excepcional, "un caso único en el mundo del fútbol». Pero en la doble traba existe un segundo requisito negativo que entra en conflicto con el primero. Para el Athletic ese requisito es el mandato de la competición: no puedes perder tu estatus de primera división. Los dos requisitos entran en conflicto porque jugadores locales mediocres pueden conducirte a la segunda división, mientras que la permanencia en primera división puede requerir a extranjeros. Desobedecer cualquiera de los dos requisitos amenaza con una desintegración catastrófica, como presenciamos en el escenario apocalíptico del Partido de la Salvación.

Para los aficionados al fútbol, lamentablemente, existe un tercer requisito negativo, que prohíbe al actor el abandono del terreno de juego. Al igual que la Trampa-22 de Heller impide que los soldados rehúyan una misión, no cabe la opción de abandonar al Athletic. Es el cierre definitivo que supone este tercer requisito lo que hace insoportable la doble traba de Bilbao: por los motivos antropológicos y sociológicos señalados, los bilbaínos sienten que deben continuar asistiendo a San Mamés. Por una parte, está la obligación simbólica con un orden superior, transmitida a través de los vínculos familiares y de amistades de toda la vida: "Nuestros jugadores son de los nuestros, un miembro de la familia, un amigo, un vecino. Los hemos visto crecer aquí. ¿Cómo podríamos abandonarlos?». Por otro lado, siguen yendo porque el disfrute de las victorias ocasionales tiene un sabor especial. Es más, el disfrute no depende estrictamente de ganar; incluso una derrota 1-4 en una final de copa (2009) sumió a Bilbao en el frenesí. «Mereció la pena esperar veinticinco años por ese momento», me dijeron muchos. "Aunque perdimos, fue el mejor día de mi vida». Ya sea por la obligación simbólica o por el vértigo del disfrute, el abandono del terreno de juego es imposible.

"¿Por qué sigo volviendo? ¿Por qué soy masoquista?» se preguntan los bilbaínos. La ciudad está atrapada en lo que Copjec denominaría el «narcisismo del masoquismo moral» (2004: 57): el "esfuerzo obediente pero inevitablemente masoquista de hallar placer en amar un ideal al cual [el presente sujeto] es inferior, lo que le causa una sensación de culpabilidad» (ibídem). Es duro amar a un equipo perdedor, y más incluso cuando la larga sombra de su glorioso pasado es un recordatorio constante de un antiguo ego ideal. Pero en fecha tan temprana como 1932, Alejandro de la Sota ya escribió sobre el «placer sentimental de saber ser perdedores» (1932: xiii). La comunidad del Athletic se ha internalizado ese placer; como afirmo el propio Williams recientemente, un jugador puede «salir fuera y ganar títulos o más dinero, pero eso no da la felicidad" (apud Rivas, 2019). Mientras que otras comunidades abandonan a sus equipos por su pobre rendimiento, los aficionados del Athletic siguen Ilenando San Mamés compulsivamente. No teniendo la opción de abandonar a «nuestros chicos», la superación de sus dobles vínculos pasa para los aficionados del Athletic por hallar placer en aquellas y disfrutar una moralidad en esencia dolorosa: "tenemos que perder para ganar».

\section{BIBLIOGRAFÍA}

Agiriano, J. (2007a). Noto mucha frialdad y mucho desencanto entre los socios. Entrevista con Fernando Astorqui. El Correo, 2 de julio de 2007. Disponible en: https:// www.elcorreo.com/vizcaya/20070702/deportes/athletic/astorqui-noto-muchodesencanto-20070702.html. Última consulta: 11/01/2020. 
Agiriano, J. (2007b). Una regla con excepciones. El Correo, 7 de julio de 2007. Disponible en: https://www.elcorreo.com/vizcaya/20070707/deportes/athletic/regla-excepciones20070707.html. Última consulta: 11/01/2020.

Aquino, M. (2017). A Panther Among Lions: Iñaki Williams, Race and Basque Identity at Athletic Club de Bilbao. Sport, Identity and Nationalism in the Hispanic World, SIBA, 4, 119136.

Baroja, C. J. (2009). The Basques. Reno, NV: Center for Basque Studies.

Capetillo, J. A. P. (2012). Sí, somos distintos. El Correo, 26 de septiembre de 2012. Disponible en: www.canalathletic.com/noticias/2012-09-26/somos-distintos-20120926.html. Última consulta: 16/10/2014.

Carlos Castillo, J. (2007). Play fresh, play local: the case of Athletic de Bilbao. Sport in Society, 10(4), 680-697.

Conversi, D. (1997). The Basques, the Catalans, and Spain: Alternative Routes to Nationalist Mobilization. Reno, NV: University of Nevada Press.

Copjec, J. (2004). Imagine There's No Woman: Ethics and sublimation. Cambridge, MA: MIT Press.

Gallop, R. (1970). The Book of the Basques. Reno, NV: University of Nevada Press.

Giulianotti, R. (1999). Football: A Sociology of the Global Game. Cambridge: Polity Press.

Greenwood, D. (1977). Continuity in change: Spanish Basque ethnicity as a historical process. En J. E. Milton (Ed.). Ethnic Conflicts in the Western World (pp. 81-103). Ithaca, NY: Cornell University Press.

Groves, M. (2011). Resisting the globalization, standardization and rationalization of football: my journey to Bilbao. Soccer $\in$ Society, 12(2), 265-278.

Halliwell, M. (2004). Images of Idiocy: The Idiot Figure in Modern Fiction and Film. Farnham: Ashgate Publishing.

Heiberg, M. (1980). Basques, anti-basques and the moral community. En R. Grillo (Ed.). 'Nation' and 'State' in Europe (pp. 45-60). Nueva York: Academic Press.

Heller, J. (1961). Catch-22. New York: Simon \& Schuster.

Hobsbawm, E., y Ranger, T. O. (1992). The Invention of Tradition. Cambridge: Cambridge University Press.

Humboldt, W. (1821). Prüfung der Untersuchungen über die Urbewohner Hispaniens vermittelst der vaskischen Sprache. Berlín: Bei Ferdinand Dümmler.

Kasmir, S. (2002). «More Basque than you!» Class, youth and identity in an industrial Basque town. Global Studies in Culture and Power, 9, 39-69.

Krichko, K. (2019) «Inaki Williams blazes a trail at Spain's historic Athletic Club: «l have in my blood what it means to be Basque». ESPN, 21 de Agosto 2019. Disponible en: https:// www.espn.com/soccer/spanish-primera-division/story/3912114/inaki-williamsblazes-a-trail-at-spains-historic-athletic-club----i-have-in-my-blood-what-it-meansto-be-basque. Última consulta: 11/11/2019. 
Laplanche, J., y Pontalis, J. B. (1986). Fantasy and the origins of sexuality. En V. Burgin, J. Donald y C. Kaplan (Eds.). Formations of Fantasy (pp. 5-34). Nueva York: Methuen.

MacClancy, J. (1996). Nationalism at play: the Basques of Vizcaya and Athletic Bilbao. Oxford: Berg Publisher Ltd.

MacClancy, J. (1993) Biological Basques, sociologically speaking. En M. Chapan (Ed.). Social and Biological Aspects of Ethnicity (pp. 92-129). Oxford: Oxford University Press.

Maia, J. (2013). «Escritor, bertsolari gipuzkoano y athleticzale». En E. Rodrigalvarez (Ed.). Historias de San Mamés (pp. 177-179). Bilbao: Athletic Club.

O'Brien, J. (2014). "Shades of Basqueness»: Football, politics and ethnicity in the Basque Country. En K. Dashper, T. Fletcher y N. Mccullough (Eds). Sports Events, Society and Culture (pp. 160-173). London: Routledge.

Ortiz-Osés, A., y Mayr, F. K. (1980). El matriarcalismo vasco: reinterpretación de la cultura vasca. Bilbao: Universidad de Deusto.

Payne, S. G. (1975). Basque Nationalism. Reno, NV: University of Nevada Press.

Rivas, J. (2019) Iñaki Williams: "A los 12 años llegué un día a casa y no había para comer». El País, 16 de agosto 2019. Disponible en: https://elpais.com/deportes/2019/08/15/ actualidad/1565882193_077676.html. Última consulta: 11/09/2019.

Salaburu, P. (2007). ¿La elección del central o la elección central? El Correo, 11 de julio de 2007, https://www.elcorreo.com/vizcaya/20070711/deportes/athletic/eleccioncentral-eleccion-central-20070711.html. Última consulta: 11/09/2019.

Soriano, F. (2012). Goal: The Ball Doesn't Go In By Chance. Basingstoke: Palgrave Macmillan.

Sota, A. de la. (1932). Divagaciones que nos trae el foot-ball. Bilbao: Editorial Vasca.

Turner, V. W. (1969). The Ritual Process: Structure and Anti-Structure. Chicago, IL: Aldine.

Ugarte, P. (2007). Filosofía e identidad. El Correo, 23 de julio de 2007. Disponible en: https:// www.elcorreo.com/vizcaya/20070708/deportes/athletic/filosofia-identidad-20070708. html. Última consulta: 11/09/2019.

Urla, J. (1993). Cultural politics in an age of statistics: numbers, nations, and the making of Basque identity. American Ethnologist, 20(4), 818-43.

Urla, J. (1995). Outlaw language: creating alternative public spheres in Basque free radio. Pragmatics, 5(2), 245-61.

Walton, J. K. (2011). Sport and the Basques: constructed and contested identities, 18761936. Journal of Historical Sociology, 24(4), 451-471.

Žižek, S. (2006). How to Read Lacan. Nueva York: W. W. Norton \& Company.

Zulaika, J. (1996). Del cromañón al carnaval: los vascos como museo antropológico. San Sebastián-Donostia: Erein. 